\title{
An analytical model for soil-atmosphere feedback
}

\author{
B. Schaefli ${ }^{1,2}$, R. J. van der Ent ${ }^{2}$, R. Woods ${ }^{3}$, and H. H. G. Savenije ${ }^{2}$ \\ ${ }^{1}$ Laboratory of Ecohydrology (ECHO), School of Architecture, Civil and Environmental Engineering (ENAC), \\ Ecole Polytechnique Fédérale de Lausanne (EPFL), Lausanne, Switzerland \\ ${ }^{2}$ Water Resources Section, Delft University of Technology (TU Delft), Delft, The Netherlands \\ ${ }^{3}$ National Institute for Water and Atmospheric Research (NIWA), Christchurch, New Zealand \\ Correspondence to: B. Schaefli (bettina.schaefli@epfl.ch)
}

Received: 30 August 2011 - Published in Hydrol. Earth Syst. Sci. Discuss.: 7 September 2011

Revised: 4 May 2012 - Accepted: 28 May 2012 - Published: 5 July 2012

\begin{abstract}
Soil-atmosphere feedback is a key for understanding the hydrological cycle and the direction of potential system changes. This paper presents an analytical framework to study the interplay between soil and atmospheric moisture, using as input only the boundary conditions at the upstream end of trajectory, assuming advective moisture transport with average wind speed along this trajectory and vertical moisture exchange with the soil compartment of uniform vertical properties. Precipitation, evaporation from interception and runoff are assumed to depend through simple functional relationships on the soil moisture or the atmospheric moisture. Evaporation from soil moisture (including transpiration) depends on both state variables, which introduces a nonlinear relationship between the two compartments. This nonlinear relationship can explain some apparently paradoxical phenomena such as a local decrease of precipitation accompanied by a runoff increase.

The solutions of the resulting water balance equations correspond to two different spatial moisture regimes showing either an increasing or a decreasing atmospheric moisture content along a trajectory starting at the coast, depending on boundary conditions and parameters. The paper discusses how different model parameters (e.g. time scales of precipitation, evaporation or runoff) influence these regimes and how they can create regime switches. Such an analysis has potential to anticipate the range of possible land use and climate changes or to interpret the results of complex land-atmosphere interaction models. Based on derived analytical expressions for the Horton index, the Budyko curve and a precipitation recycling ratio, the analytical framework opens new perspectives for the classification of hydrological systems.
\end{abstract}

\section{Introduction}

Feedback processes between the land surface and the atmosphere have long been recognized as being key to understanding the hydrological cycle, e.g. for local and regional variability of precipitation (Tuinenburg et al., 2011; Eltahir, 1998; DeAngelis et al., 2010) or for the study of different sources of precipitation at continental scales, i.e. for moisture recycling studies (Burde and Zangvil, 2001; Eltahir and Bras, 1994; Trenberth, 1998). Recent results in this field demonstrate that on large continental areas, moisture recycling can be a dominant mechanism to sustain precipitation (e.g. Van der Ent et al., 2010).

Nevertheless, explicit representation or assessment of moisture recycling receives limited attention in classical meteorological or hydrological models. From a meteorological perspective, this is not surprising since advective moisture fluxes are often an order of magnitude larger than evaporative fluxes (e.g. Schär et al., 1999), especially at small spatial scales. In addition, the focus is often on local precipitation triggering mechanisms (e.g. the effect of soil moisture conditions on boundary layer stability and precipitation, Seneviratne et al., 2010) rather than on mechanisms that sustain rainfall as in the present paper. Moreover the calculation of evaporation is complex as it depends in a non-trivial way on soil moisture, atmospheric moisture, land roughness, energy exchange, and indirectly on topography, soil properties and land use, all of which are highly heterogeneous and sometimes variable in time. From a hydrological perspective, climate is generally considered as an exogenous forcing in terms of precipitation and potential evaporation. This viewpoint is a natural choice when analyzing individual catchments of up to few thousand square kilometers. However, if 
we model the hydrologic cycle at continental scales, if we analyze climate or land use change impacts or if we try to classify catchments across hydroclimatic regions (Wagener et al., 2007), we can only benefit from understanding the coupled soil-atmosphere system and moisture recycling.

Such insights can be obtained by methods ranging from analyzing the isotopical origin of precipitation (Tian et al., 2007) to analytical studies (e.g. Lintner et al., 2012) or different numerical techniques (see a discussion in Dominguez et al., 2006). Numerical studies commonly use e.g. monthlong integration of regional or global coupled atmosphereland surface models to analyze moisture feedbacks by varying soil and vegetation parameters and boundary conditions (Schär et al., 1999; Dirmeyer et al., 2006; Kunstmann and Jung, 2007). Studying the sensitivity of such models can give valuable insights into these feedbacks, in particular in the context of multi-model studies (Koster et al., 2004). It is, however, difficult to trace back how a parameter change modifies, directly or indirectly, a system output such as evaporation. This is, in contrast, the strength of analytical recycling models that quantify e.g. the contribution of local evaporation to total precipitation based on a set of simple balance equations used to compute water budgets based on observed or reanalysis data of evaporation and precipitation (e.g. Burde and Zangvil, 2001; Dominguez et al., 2006).

In this paper, we present a different type of analytical model: it describes the hydrologic cycle at points along an atmospheric trajectory using only the atmospheric storage at the upstream boundary (at the coast) as input. Atmospheric moisture is transported along the trajectory with advection and exchanged with the soil through precipitation and evaporation which are formulated as functions of atmospheric and soil moisture. Evaporation from transpiration and intercepted water are quantified separately and the model also accounts for runoff. It may be considered a "toy model" that can be used to analyze moisture regimes and their sensitivity to interception, advected moisture, soil moisture and runoff and evaporation time scales.

In the following, we first present our coupled model, its analytical solutions and the possible moisture regimes along a flow path (Sect. 2). To illustrate the use of the model, we present three different types of analyses (Sect. 3): (i) the effect of parameter changes on moisture profiles along an atmospheric moisture flow path; (ii) the relationship between atmospheric moisture and the Horton index and the Budyko curve, which are used to describe the hydrologic behaviour of a system (Troch et al., 2009); and (iii) the relationship between the key parameters and precipitation recycling. Before summarizing our main conclusions (Sect. 5), we briefly discuss the potentialities and limitations of the proposed model (Sect. 4).
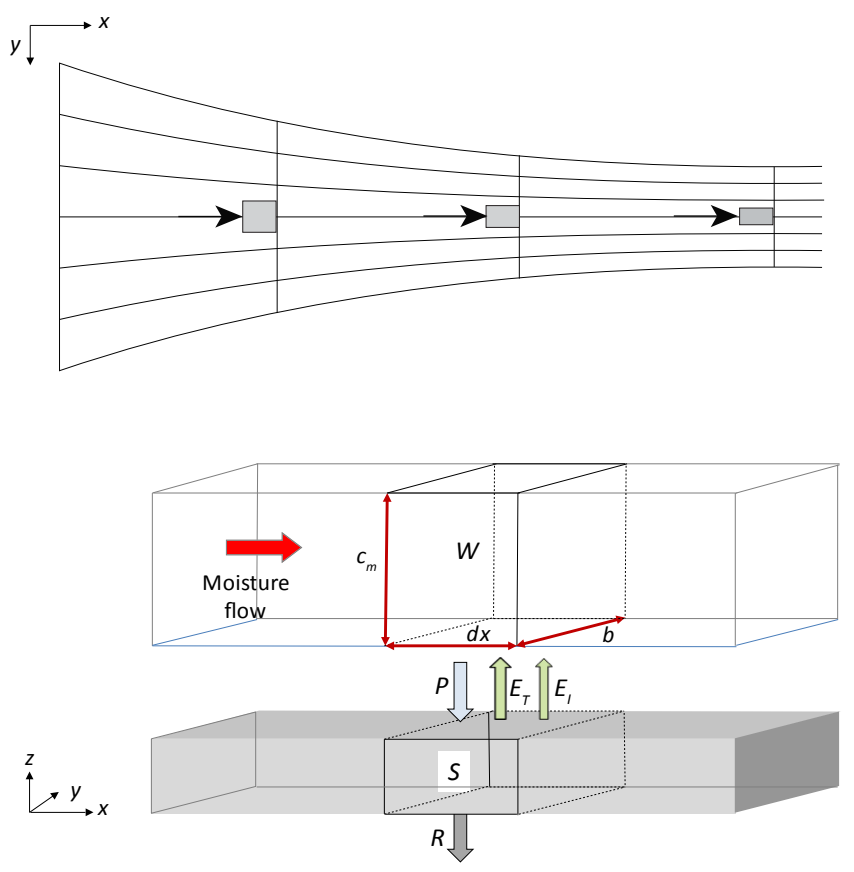

Fig. 1. Sketch of the model (top view and a side view); note that lateral transport through advection is only modelled for the atmospheric control volume, not for the soil.

\section{Method}

We adopt an approach based on dominant atmospheric moisture trajectories, which can be obtained from data (e.g. Dominguez and Kumar, 2008; Van der Ent et al., 2010). An atmospheric moisture trajectory starts at the coast; the positive $x$-direction is pointed inland. At a given location $x$, we assume that the atmosphere and the soil compartment are each composed of a single, well-mixed layer connected by the vertical exchange fluxes of precipitation and evaporation (see Fig. 1). Lateral transport through advection is modelled only for atmospheric moisture; for soil moisture, lateral transport is neglected. The only influx of water to the soil compartment is precipitation, the outfluxes are runoff, groundwater recharge and total evaporation (evaporation from the soil surface and transpiration). The boundary condition of the atmospheric compartment at the upstream boundary of a trajectory is given by atmospheric moisture at the coast.

\subsection{Modelling framework}

Consider the control volume $V$, a tropospheric column of mass $M$

$M=\varpi V W=\varpi V \frac{C}{c_{\mathrm{m}}}$,

where $\varpi\left[\mathrm{M} / \mathrm{L}^{3}\right]$ is the density of water and $W[-]$ is the relative atmospheric moisture filling, defined as the ratio of 
precipitable water $C[\mathrm{~L}]$ to the maximum water holding capacity of the control volume $c_{\mathrm{m}}[\mathrm{L}] . W$ is in fact a relative humidity measure integrated over the entire height of the column (called column-relative humidity by Bretherton et al., 2004). $C$ and $c_{\mathrm{m}}$ are the height integrals of specific humidity and of saturation specific humidity respectively.

The conservation of mass for $M$ reads as (see also Fig. 1):

$$
\begin{aligned}
\frac{\partial(V W)}{\partial t} & =-u_{x} \frac{\partial(V W)}{\partial x}+D_{x} \frac{\partial^{2}(V W)}{\partial x^{2}} \\
& -\left(P-E_{\mathrm{T}}-E_{\mathrm{I}}\right) b \mathrm{~d} x
\end{aligned}
$$

where $P\left[\mathrm{LT}^{-1}\right]$ is the precipitation, $E_{\mathrm{T}}\left[\mathrm{LT}^{-1}\right]$ is the evaporative flux from the soil moisture compartment to the atmosphere mostly due to the transpiration of vegetation (but it also includes soil evaporation) and $E_{\mathrm{I}}$ is the evaporative flux from water intercepted on vegetation, forest floor or bare surface. $b \mathrm{~d} x\left[\mathrm{~L}^{2}\right]$ is the area of the control volume through which these fluxes pass. $D_{x}\left[\mathrm{~L}^{2} \mathrm{~T}^{-1}\right]$ is the dispersion coefficient and $u_{x}\left[\mathrm{LT}^{-1}\right]$ the wind speed in the flow direction, which should be seen as an effective wind speed (i.e. moisture weighted), such as used, e.g. by Goessling and Reick (2011). Note that all state and flux variables depend on space and time but for reasons of readability, we use the short forms $W=W(x, t)$ where appropriate.

Horizontal atmospheric mixing rates in the troposphere are typically in the order of magnitude of $10^{4} \mathrm{~m}^{2} \mathrm{~s}^{-1}$ (e.g. Pisso et al., 2009). Given the very small horizontal concentration gradients for atmospheric moisture $C$ [L] (a few $\mathrm{mm}$ per $100 \mathrm{~km}$, i.e. a gradient of $10^{-7} \mathrm{~m} \mathrm{~m}^{-1}$, (e.g. Randel et al., 1996)), the dispersive flux $F_{\mathrm{d}}=D_{x} \frac{\mathrm{d} C}{\mathrm{~d} x}$, has an order of magnitude of $10^{-3} \mathrm{~m}^{2} \mathrm{~s}^{-1}$. Assuming average horizontal wind speeds of the order of $10 \mathrm{~m} \mathrm{~s}^{-1}$ and atmospheric moisture storage in the troposphere of the order of $10^{-2} \mathrm{~m}$, it is readily apparent that the advective flux $F_{\mathrm{a}}=u_{x} C \gg F_{\mathrm{d}}$. We therefore neglect dispersion at the spatio-temporal scales considered here.

Expressing the control volume height in terms of a constant water holding capacity $c_{\mathrm{m}}$, i.e. $V=c_{\mathrm{m}} b \mathrm{~d} x$, the lefthand term reads as

$$
\frac{\partial(V W)}{\partial t}=W \frac{\partial V}{\partial t}+V \frac{\partial W}{\partial t}=W c_{\mathrm{m}} \mathrm{d} x \frac{\partial b}{\partial t}+c_{\mathrm{m}} b \mathrm{~d} x \frac{\partial W}{\partial t},
$$

and we can re-write Eq. (2) as

$$
\begin{aligned}
\frac{\partial W}{\partial t}+ & u_{x} \frac{\partial W}{\partial x}=-\frac{1}{c_{\mathrm{m}}}\left(P-E_{\mathrm{T}}-E_{\mathrm{I}}\right) \\
& -\frac{1}{b} W\left(\frac{\partial b}{\partial t}+u_{x} \frac{\partial b}{\partial x}\right),
\end{aligned}
$$

Note that the control volume $V$ refers to the moisture carrying part of the tropospheric column only. Equation (4) can be written in a Lagrangian framework using the substantial or Lagrangian derivative (Trenberth, 2009):

$$
\frac{\mathrm{d} f}{\mathrm{~d} t}=\frac{\partial f}{\partial t}+u_{x} \frac{\partial f}{\partial x}=u_{x} \frac{\mathrm{d} f}{\mathrm{~d} x},
$$

$$
\frac{\mathrm{d} W}{\mathrm{~d} t}=u_{x} \frac{\mathrm{d} W}{\mathrm{~d} x}=-\frac{1}{c_{\mathrm{m}}}\left(P-E_{\mathrm{T}}-E_{\mathrm{I}}\right)-u_{x} W \frac{1}{b} \frac{\mathrm{d} b}{\mathrm{~d} x} .
$$

The last term in the above equation encodes the net change of the shape of the moisture carrying trajectory (of its width) along $x$ (see Fig. 1), corresponding either to a convergence $\left(\frac{\mathrm{d} b}{\mathrm{~d} x}<0\right)$ or divergence $\left(\frac{\mathrm{d} b}{\mathrm{~d} x}>0\right)$. In the case of convergence, the narrowing of the control width results in an increased concentration of water in the control volume, which results in an apparent inflow of moisture. For simplicity, this inflow due to convergence is termed relative lateral inflow, $I=-u_{x} W \frac{1}{b} \frac{\mathrm{d} b}{\mathrm{~d} x}\left[\mathrm{~T}^{-1}\right]$.

For soil moisture, we assume absence of lateral transport and of volume change; the conservation of mass becomes

$$
\frac{\partial S}{\partial t}=P-E_{\mathrm{I}}-E_{\mathrm{T}}-R,
$$

where $S[\mathrm{~L}]$ is the soil moisture and $R\left[\mathrm{LT}^{-1}\right]$ represents all water that is lost from the soil compartment through other processes than evaporation, i.e. it includes slow and rapid discharge processes and groundwater recharge. In the following, we refer to $R$ as runoff. We assume a simple linear relationship to $S$ through a residence time $\tau_{\mathrm{q}}$ :

$R=\frac{1}{\tau_{\mathrm{q}}} S$.

This corresponds to the frequently used assumption of a linear relationship between slow discharge or recharge processes and soil moisture (e.g. Fenicia et al., 2006). $\tau_{\mathrm{q}}[\mathrm{T}]$ is the time scale of the sum of these processes. We assume here that rapid discharge processes (e.g. surface runoff) are negligible.

The formation of precipitation in the atmosphere is known to be a non-trivial physical process. Savenije (1995b) suggested to model precipitation as a linear function of the atmospheric moisture $C$ above a certain moisture threshold $c_{\mathrm{t}}$, corresponding to the moisture that always remains in the atmosphere (Trenberth et al., 2003). Analyzing moisture and precipitation over tropical oceans, Bretherton et al. (2004) proposed an exponential relationship between $P$ and $W$ at daily to monthly timescales. In order to make the model analytically tractable, we adopt here the simplifying assumption that precipitation has a squared relationship between $P$ and $W$, which appears to capture their relationship reasonably well (see Supplement, Fig. S1).

$P=\frac{1}{\tau_{\mathrm{p}}} C W=\frac{c_{\mathrm{m}}}{\tau_{\mathrm{p}}} W^{2}$,

where $\tau_{\mathrm{p}}[\mathrm{T}]$ is the effective time scale of the precipitation process.

Interception is generally also assumed to be a threshold process at an hourly to daily time scale (e.g. Gerrits et al., 
2010). De Groen and Savenije (2006) derived an expression for monthly interception as a function of monthly precipitation and number of rain days. However, to be able to derive analytical solutions, we retain here the simple linear relationship between interception and precipitation with the interception parameter $\alpha$ :

$E_{\mathrm{I}}=\alpha P$.

Following classical transpiration formulations in rainfallrunoff models (e.g. Clark et al., 2008), $E_{\mathrm{T}}$ is modelled as a function of potential evaporation $E_{\mathrm{P}}$ and the degree of soil saturation $S / s_{\mathrm{m}}$

$E_{\mathrm{T}}=E_{\mathrm{P}} \frac{S}{s_{\mathrm{m}}}$,

where $S=S(x, t)[\mathrm{L}]$ is the actual soil moisture storage and $s_{\mathrm{m}}[\mathrm{L}]$ the maximum soil moisture storage [L]. $E_{\mathrm{P}}[\mathrm{L}]$ depends on the actual meteorological conditions. Its estimation is generally based on the Penman-Monteith equation (Monteith, 1965) (or modifications thereof), which corresponds to a combination of the available energy for evaporation (balance of net radiation and sensible heat flux to the soil) and of the aerodynamic evaporation potential accounting for average wind speed, surface resistance and air saturation deficit (e.g. Howell and Evett, 2004). A well-known simplification of this approach is the Priestley-Taylor equation (Priestley and Taylor, 1972), which replaces the aerodynamic term by a constant factor.

In the present modelling framework, the saturation deficit can be expressed as $c_{\mathrm{m}}-C=c_{\mathrm{m}}(1-W)$ and can, thus, be included explicitly in the estimation of $E_{\mathrm{P}}$. All other components and namely the available energy have to be parameterized. We propose the following parameterization:

$E_{\mathrm{P}}=\frac{1}{\tau_{\mathrm{e}}} e_{\mathrm{m}}(1-W)$,

where $e_{\mathrm{m}}[\mathrm{L}]$ is the maximum amount of water that could be transpired over the time scale of evaporation, $\tau_{\mathrm{e}}$, if $W$ was not limiting. $e_{\mathrm{m}}$ summarizes the water holding capacity of the atmospheric column $\left(c_{\mathrm{m}}\right)$, the available energy as well as aerodynamic conditions; accordingly, it will depend on temperature and, more generally, on the season. Note that $E_{\mathrm{P}}$ is defined as the potential evaporation for transpiration. The total potential evaporation includes the energy available for interception, $E_{\mathrm{I}}$.

After substitution of Eqs. (9), (10) and (13) into Eq. (6) and into Eq. (7), the coupled water balance model becomes:

$E_{\mathrm{T}}=\frac{1}{\tau_{\mathrm{e}}} \frac{e_{\mathrm{m}}}{s_{\mathrm{m}}}(1-W) S$.

$\tau_{\mathrm{e}}$ represents the time scale of transpiration of the vegetation, i.e. the amount of time that the vegetation would require to transpire $e_{\mathrm{m}}$ if neither atmospheric moisture nor soil moisture was limiting ( $W=0, S=s_{\mathrm{m}}$ ); this value is characteristic for a given vegetation-soil system.

Evaporation as parameterized in Eq. (13) is limited by the available soil moisture as well as by the capacity of the atmosphere to receive water and, thus, couples the two compartments.

Combining the above equations, the coupled water balance model becomes

$u_{x} \frac{\mathrm{d} W}{\mathrm{~d} x}=-\frac{1}{c_{\mathrm{m}}}\left((1-\alpha) \frac{c_{\mathrm{m}}}{\tau_{\mathrm{p}}} W^{2}-\frac{1}{\tau_{\mathrm{e}}} \frac{e_{\mathrm{m}}}{s_{\mathrm{m}}}(1-W) S\right)+I$

$\frac{\partial S}{\partial t}=(1-\alpha) \frac{c_{\mathrm{m}}}{\tau_{\mathrm{p}}} W^{2}-\frac{1}{\tau_{\mathrm{e}}} \frac{e_{\mathrm{m}}}{s_{\mathrm{m}}}(1-W) S-\frac{1}{\tau_{\mathrm{q}}} S$.

Recall that in the above equations we use the short notation $W, S$ and $I$ for $W(t, x), S(t, x)$ and $I(t, x)$.

\subsection{Analytical solution}

Soil moisture is well-known to undergo a seasonal cycle of gradual filling and emptying, depending on the seasonality of precipitation and of vegetation growth. We, thus, assume that this temporal cycle can roughly be described by a constant soil moisture increase during the wet season and a constant soil moisture decrease during the dry season, which translates into an approximation of $\frac{\partial S}{\partial t}$ with a constant rate of change $\xi_{s}$ for each of the seasons.

This assumption of $\xi_{s}=$ cst is similar to linearizing a differential equation, where one assumes some variable $z=z\left(Y_{0}\right)$ when in fact $z=z(Y)$. Here we use $\frac{\partial S}{\partial t}=\frac{\partial S}{\partial t} \mid\left(S=S_{0}\right)=\xi_{s}$.

Equation (15) can be re-written as:

$\frac{S}{c_{\mathrm{m}}}=\left((1-\alpha) \frac{\tau_{\mathrm{q}}}{\tau_{\mathrm{p}}} W^{2}-\frac{\tau_{\mathrm{q}}}{c_{\mathrm{m}}} \xi_{s}\right) \frac{1}{1+\kappa(1-W)}$,

where we have introduced $\kappa=\frac{e_{\mathrm{m}} \tau_{\mathrm{q}}}{s_{\mathrm{m}} \tau_{\mathrm{e}}}$. This parameter $\kappa$ corresponds to the ratio of maximum potential evaporation $e_{\mathrm{m}} / \tau_{\mathrm{e}}$ to maximum runoff $s_{\mathrm{m}} / \tau_{\mathrm{q}}$ and is a parameter which controls the spatial dynamics.

Substituting the above $S / c_{\mathrm{m}}$ into Eq. (14) yields a first order ordinary differential equation for $W$ :

$$
\begin{gathered}
u_{x} \frac{\mathrm{d} W}{\mathrm{~d} x}=-\frac{(1-\alpha)}{\tau_{\mathrm{p}}} \frac{1}{1+\kappa(1-W)} \\
\left(W^{2}+\frac{\tau_{\mathrm{p}} \kappa \xi_{s}(1-W)}{(1-\alpha) c_{\mathrm{m}}}\right)+I
\end{gathered}
$$

If we assume that $u_{x}, \tau_{\mathrm{p}}, \tau_{\mathrm{q}}, \tau_{\mathrm{e}}, e_{\mathrm{m}}, s_{\mathrm{m}}, I$ are all constant in space, the solution of Eq. (17) is

$$
\frac{x}{L}=-\log \left[\left(\frac{W(x)-W_{1}}{W_{0}-W_{1}}\right)^{A^{*}}\left(\frac{W(x)-W_{2}}{W_{0}-W_{2}}\right)^{B^{*}}\right]
$$

where $L=u_{x} \frac{\tau_{\mathrm{p}}}{1-\alpha}$ is the horizontal length scale for this solution, $W_{0}$ is the atmospheric moisture content at $x=0$ and $W_{1}$ 
and $W_{2}$ are the two equilibrium points of Eq. (17) that correspond to the solutions in the special case that $\mathrm{d} W / \mathrm{d} x=0$. They are given by

$$
\begin{aligned}
W_{1,2} & =\frac{1}{2}\left(\kappa\left(D^{*}-I^{*}\right)\right. \\
& \left. \pm \sqrt{\kappa^{2}\left(D^{*}-I^{*}\right)^{2}-4 \kappa\left(D^{*}-I^{*}\right)+4 I^{*}}\right)
\end{aligned}
$$

where we have used the scaled moisture convergence $I^{*}$

$I^{*}=\frac{\tau_{\mathrm{p}}}{1-\alpha} I$

and the scaled soil moisture variation $D^{*}$

$D^{*}=\frac{\tau_{\mathrm{p}}}{(1-\alpha) c_{\mathrm{m}}} \xi_{s}$

The dimensionless quantity $D^{*}$ relates the soil moisture variation $\xi_{s}$ to the maximum precipitation input to the soil $(1-\alpha) c_{\mathrm{m}} / \tau_{\mathrm{p}}$.

The exponents $A^{*}$ and $B^{*}$ in Eq. (18) are

$A^{*}=\frac{1+\kappa-\kappa W_{1}}{W_{1}-W_{2}}$

$B^{*}=\frac{-1-\kappa+\kappa W_{2}}{W_{1}-W_{2}}$.

It holds that $A^{*}+B^{*}=-\kappa, W_{1}>W_{2}$ and $W_{1}+W_{2}=$ $\kappa\left(D^{*}-I^{*}\right)$.

The behaviour of Eq. (18) and the shape of $W(x)$ is further discussed hereafter. The corresponding soil moisture content is given in Eq. (16).

\subsection{Behaviour of the analytical solution}

The implicit solution of Eq. (18) shows that $W(x)$ is either monotonically increasing along $x$ or decreasing, depending on the model parameters and the boundary condition $W_{0} . W_{1}$ is the equilibrium moisture for $x \rightarrow+\infty$ and $W_{2}$ the equilibrium moisture for $x \rightarrow-\infty$. It follows that if $W_{0}>W_{2}$, then $W$ will converge to $W_{1}$ as $x \rightarrow+\infty$, either from above or below, depending on whether $W_{0}>W_{1}$ or $W_{0}<W_{1}$. If $W_{0}<W_{2}$, then $W$ will reach 0 at a finite positive value of $x$, and the mathematical solution is not physically meaningful beyond that $x$.

Given that it has to hold that $0 \leq W(x) \leq 1$, a physical solution only exists if there is an equilibrium moisture $W_{1} \in[0,1]$ that is a real number. The conditions on the model parameters for such a $W_{1}$ to exist are summarized in Table 1. This table also summarizes the conditions for $W_{2} \in[0,1]$, which are relevant for the occurrence of the above special situation $W_{0}<W_{2}$.

In the following, we only discuss the physically possible situation where $W(x)$ starts at the upstream boundary condition $W_{0}$ and then either increases or decreases to reach
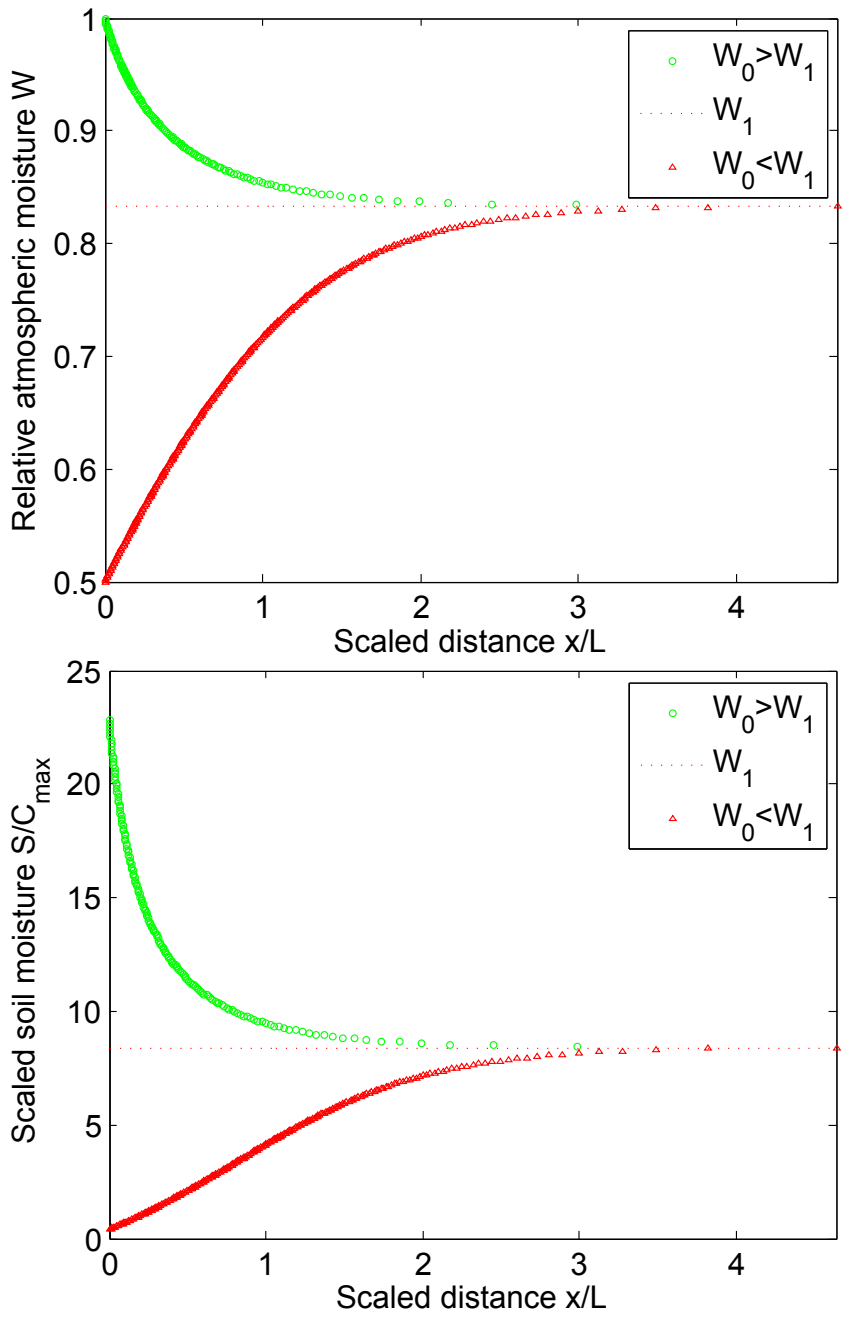

Fig. 2. Moisture profiles obtained with default parameter values (Table $2, L=5400 \mathrm{~km}$ ) for $W_{0}=0.5$ (increasing regime) and $W_{0}=$ 1.0 (decreasing regime); the top plot shows atmospheric moisture, the bottom plot soil moisture.

the equilibrium point $W_{1}$. These two regimes are illustrated in Fig. 2. The soil moisture profile always shows the same regime as the atmospheric moisture profile. Hereafter, we first present the solutions for some special cases before discussing in detail the behaviour of the coupled system in Sect. 3.

\subsubsection{Case 1a: no moisture convergence, stationary soil moisture}

If $I=0$ and $\xi_{s}=0$, then the solution of Eq. (17) is

$\frac{x}{L}=(1+\kappa)\left(\frac{1}{W}-\frac{1}{W_{0}}\right)+\kappa \log \left(\frac{W}{W_{0}}\right)$

We have that $\frac{x}{L}>0$ for $W<W_{0}$ and $\frac{x}{L}<0$ for $W>W_{0}$, which implies $W<W_{0}$, i.e. the relative atmospheric moisture can only decrease if traveling inland; this loss of 
atmospheric moisture is a direct result of water removal from the system by the runoff process along the trajectory. The equilibrium moisture for $\frac{\mathrm{d} W}{\mathrm{~d} x}=0$ is $W=0$.

\subsubsection{Case 1b: no moisture convergence, non-stationary soil moisture}

If $I=0$ and $\xi_{s} \neq 0$, we have physical solutions (there is a physical equilibrium point $W_{1}$ ), if and only if $D^{*}<0$, which only holds if $\xi_{s}<0$, i.e. if there is soil moisture depletion.

From Eq. (17) it can be seen that $\mathrm{d} W / \mathrm{d} x>0$ for $D^{*}<$ $-W^{2} /(\kappa(1-W))$. It also holds that $-W^{2} /(\kappa(1-W)) \leq 0$ for all $W$. Accordingly, if, in absence of convergence, the moving atmospheric column finds, along its trajectory, soil columns that are on average drying out $\left(D^{*}<0, \xi_{s}<0\right.$, then the moisture content of the atmospheric column has to be increasing along its trajectory (otherwise the soil moisture depletion regime would not be sustainable). This kind of regime might occur in regions where water removal via runoff is more efficient than water input through the net influx $P-E_{\mathrm{I}}$.

\subsubsection{Case 2: scaled moisture convergence $=1$, stationary soil moisture}

If $I^{*}=1$ and $\xi_{s}=0$, Eq. (17) has the special solution $W_{1}=$ 1 , which implies that independent of the other parameter values, the atmospheric moisture can only increase if traveling inland. This special case corresponds to a setting where the atmosphere is accumulating water because moisture loss to the soil is negligible.

\subsubsection{Case 3: Low potential evaporation, high runoff}

If maximum potential evaporation $\frac{e_{\mathrm{m}}}{\tau_{\mathrm{e}}}$ is very low and maximum runoff $\frac{s_{\mathrm{m}}}{\tau_{\mathrm{q}}}$ very high so that $\kappa=\frac{e_{\mathrm{m}} \tau_{\mathrm{q}}}{s_{\mathrm{m}} \tau_{\mathrm{e}}}$ tends to zero, then $W_{1,2}= \pm \sqrt{I^{*}}, A^{*}=\left(W_{1}-W_{2}\right)^{-1}=\left(2 \sqrt{I^{*}}\right)^{-1}, B^{*}=-A^{*}$ and Eq. (18) becomes

$$
\begin{gathered}
\frac{x}{L}=-\log \left[\left(\frac{W(x)-\sqrt{I^{*}}}{W_{0}-\sqrt{I^{*}}}\right)^{\frac{1}{2 \sqrt{I^{*}}}}\right. \\
\left.\left(\frac{W(x)+\sqrt{I^{*}}}{W_{0}+\sqrt{I^{*}}}\right)^{-\frac{1}{2 \sqrt{I^{*}}}}\right]
\end{gathered}
$$

The above equation has an explicit solution:

$$
W(x)=\sqrt{I^{*}} \frac{1+B}{1-B}
$$

with

$$
B=\frac{W_{0}-\sqrt{I^{*}}}{W_{0}+\sqrt{I^{*}}}\left(\mathrm{e}^{-\frac{x}{L}}\right)^{2 \sqrt{I^{*}}}
$$

Since no moisture is returned from the soil, the moisture decay process is only driven by the precipitation of moisture from the atmosphere, convergence and interception. This special case might occur in very energy-limited environments where soil water discharge is fast. This could typically be the case in high latitude or high altitude environments.

If in addition convergence $I=0$, Eq. (24) applies and it simplifies to

$W=\frac{W_{0}}{1+W_{0} \frac{x}{L}}$,

which goes faster to zero if interception is small (recall $\left.L=u_{x} \frac{\tau_{\mathrm{p}}}{1-\alpha}\right)$. For the same slope in $W(x=0)$, it goes to zero more slowly than the often assumed exponential decay (e.g. Savenije, 1995a).

\subsubsection{Case 4: High potential evaporation, low discharge}

If maximum potential evaporation is high and maximum discharge is very low so that $\kappa$ tends to infinity (almost all precipitation is returned to the atmosphere), then Eq. (17) reduces to

$\frac{\mathrm{d} W(x)}{\mathrm{d} x}=\frac{1}{L}\left(-\frac{\tau_{\mathrm{p}} \xi_{s}}{(1-\alpha) c_{\mathrm{m}}}+I^{*}\right)$

and the solution is

$W(x)=\left(-\frac{\xi_{s}}{u_{x} c_{\mathrm{m}}}+\frac{I}{u_{x}}\right) x+W_{0}$.

This special case could occur in areas where the evaporative demand is high (energy not limiting, low relative humidity and sufficient wind for air renewal) and where soil water percolation is very low. This would typically be the case in irrigated areas in (semi-)arid climates where the water is managed such as to minimize water loss through soil water runoff.

In this case, the moisture profile along $x$ depends only on the variation of soil moisture $\xi_{s}$ and the climatic factors $u_{x}, c_{\mathrm{m}}$ and $I$. In a climate with convergence $(I>0)$, the increasing regime will prevail during the soil moisture depletion (dry) season and a switch to a decreasing regime during the wet season is only possible if convergence is low or soil moisture accumulation is very fast (short wet season).

If $I=0$, the regime only depends on $\xi_{s}$ and an increasing regime occurs during the dry season; during the wet season, a decreasing regime occurs. In this last case, the moisture accumulates in the soil before being re-evaporated into the atmosphere, which might typically be the case in an expanding wetland system in semi-arid climates.

The assumptions behind the above solution will break down at large $x$, because the atmospheric moisture content $W$ cannot exceed unity. This simply follows from the fact that very fast evaporation combined to slow soil runoff leads to too much water in the atmosphere that cannot be evacuated. Such unrealistic conditions will of course not occur in nature where any excess water would be removed by surface runoff (not included in the current model). 


\section{System behaviour}

\subsection{Plausible parameter values}

The water holding capacity $c_{\mathrm{m}}$ can be estimated based on the average amount of precipitable water in the atmosphere, which corresponds to around 50 to $80 \mathrm{~mm}$ near the equator and around 10 times less at the poles (Randel et al., 1996). The time scale of precipitation is of the order of magnitude of a few days (see, e.g. Trenberth, 1998). The time scale of transpiration can vary considerably depending on vegetation and climate; it is of the order of a few weeks to months. Runoff processes are generally slow and have a time scale much higher than evaporation (months to years). The amount of interception depends on vegetation and the rainfall regime and is of the order of magnitude of $10 \%$ up to $50 \%$ of the rainfall (de Groen and Savenije, 2006). Some authors do not treat the slow $E_{\mathrm{T}}$ and the fast $E_{\mathrm{I}}$ separately (see also Savenije, 2004), which leads to low total evaporation time scales (e.g. Trenberth, 1998).

$s_{\mathrm{m}}$ is of the order of magnitude of a few hundred $\mathrm{mm}$ (Brutsaert, 2005) and can be obtained based on a porosity estimate multiplied with the root zone depth (delimiting the zone from which vegetation can extract water). The rate of change of soil moisture, $\xi_{s}$, for different seasons is ideally obtained based on observed water balance data. An order of magnitude of $\xi_{s}$ can be obtained by dividing $s_{\mathrm{m}}$ by the length of the wet season, respectively of the dry season. The potentially evaporable water in a year ranges from a few hundred $\mathrm{mm}$ up to $2500 \mathrm{~mm}$, depending on the climate (e.g. Matsoukas et al., 2011).

Lateral convergence $I$ can be positive or negative (divergence). It corresponds to a relative humidity flux and has an absolute order of magnitude between 0 and 10 month $^{-1}$ ( $I=5$ month $^{-1}$ with $c_{\mathrm{m}}=20 \mathrm{~mm}$ corresponds to a lateral influx of $100 \mathrm{~mm} \mathrm{month}^{-1}$ ). Possible values of $I$ for physical solutions of the system have to be studied for different settings of the values of $\kappa$ and $D^{*}$ (see Table 1).

Finally, to ensure physical soil moisture values $(S \in$ $\left[0, s_{\mathrm{m}}\right]$ ) for $W_{0}$ and for $W_{1}$, it has to hold that (see Eq. 16)

$$
\frac{\xi_{s}}{c_{\mathrm{m}}} \leq \frac{1-\alpha}{\tau_{\mathrm{p}}} W_{j}^{2}
$$

and

$$
\frac{\xi_{s}}{c_{\mathrm{m}}} \geq \frac{(1-\alpha) \frac{\tau_{\mathrm{q}}}{\tau_{\mathrm{p}}} W_{j}^{2}-\frac{\tau_{\mathrm{q}}}{c_{\mathrm{m}}}}{1+\kappa\left(1-W_{j}\right)},
$$

where $W_{j}$ stands for either $W_{0}$ or $W_{1}$.

The above values and the order of magnitude of the climatic parameters discussed in Sect. 2 are summarized in Table 2. If nothing else is stated, we use the reference parameter values of Fig. 2, which illustrate how the atmospheric and soil moisture contents vary with distance downwind for
Table 1. Conditions on the parameters $\kappa, D^{*}, I^{*}$ for the existence of $W_{1} \in[0,1]$ or $W_{2} \in[0,1]$ (see Eq. 19); for simplification, we use $\chi=\kappa\left(D^{*}-I^{*}\right)$, a measure of the difference between the convergence and the rate of soil moisture change, scaled by all other process parameters. If situations 1 and 5 occur jointly with $W_{0}<$ $W_{2}$, then the solution is not physically realistic for all $x>0$ (see Sect. 2.3).

\begin{tabular}{clll}
\hline $\begin{array}{c}\text { Situation } \\
\text { number }\end{array}$ & Condition 1 & Condition 2 & Conclusion \\
\hline 1 & $\chi<0$ & $\chi<I^{*}<1$ & $W_{1} \in[0,1]$ \\
2 & $0<\chi<2$ & $\frac{1}{4} \chi(4-\chi)<I^{*}<1$ & $W_{1} \in[0,1]$ \\
3 & $\chi>2$ & - & $W_{1} \notin[0,1]$ \\
4 & $\chi<0$ & - & $W_{2} \notin[0,1]$ \\
5 & $0<\chi<2$ & $\frac{1}{4} \chi(4-\chi)<I^{*}<\chi$ & $W_{2} \in[0,1]$ \\
6 & $\chi>2$ & $1<I^{*}<\chi$ & $W_{2} \in[0,1]$ \\
\hline
\end{tabular}

a given set of parameters. Fig. 3 shows the corresponding fluxes.

The presented solution to the coupled moisture equations assumes that all parameters are constant in time and in space. To study the behaviour of a particular system, this assumption might be relaxed by discretizing the moisture trajectory into portions with constant parameter values.

\subsection{Relationship between $W$ and $S$}

The relationship between the two state variables $W$ and $S$ depends on all hydroclimatic parameters (see Eq. 16). For plausible parameter values, the soil moisture increases slower than the atmospheric moisture for low values but goes faster to its maximum. Figure 4 shows a dimensionless plot of $S / \max (S)$ against $W / \max (W))$ for different parameter values (see Table 3), for the two cases of $\xi_{s}=0$ and $\xi_{s}=10 \mathrm{~mm}$ month ${ }^{-1}$. The figures also show the case of no coupling term $(1-W)$ in Eq. (13); in this case the degree of soil filling for a given relative atmospheric moisture would be overestimated with respect to the case with coupling. This overestimation would be even stronger if precipitation was parameterized as a linear function of $W$ (Fig. 4). If, in addition, $\xi_{s}=0$, then the soil storage would behave exactly like the atmospheric storage (Fig. 4, top); in all other cases, the relative filling of the soil is lower than the relative filling of the atmospheric storage.

The functional relationship between $W$ and $S$ represents a valuable tool to derive first order estimates of the effect of process modifications on both compartments. Since this relationship is nonlinear, a parameter modification will have a rather different effect on the profile of $W$ and of $S$ and on the related fluxes. If the evaporation process becomes faster (an assumed effect of increasing temperature), the atmospheric moisture and, thus, precipitation increases along the entire trajectory (see Fig. 5a), which is a commonly assumed and observed effect (see Trenberth, 1998, and references therein). 
Table 2. Order of magnitude of parameter values used for numerical applications and default values used if nothing else is stated. The value for $e_{\mathrm{m}}$ is obtained based on estimates of the maximum annual potential evaporation, $E_{\mathrm{pm}}$, as $e_{\mathrm{m}}=\tau_{\mathrm{e}} E_{\mathrm{pm}}$.

\begin{tabular}{llrrrl}
\hline Parameter & Unit & Min. val. & Max. val. & Def. val. & Meaning \\
\hline$W_{0}$ & - & 0 & 1 & 0.8 & Initial atmospheric moisture \\
$\tau_{\mathrm{p}}$ & days & 5 & 20 & 10 & Precipitation time scale \\
$\tau_{\mathrm{e}}$ & months & 0.5 & 4 & 1 & Evaporation time scale \\
$\tau_{\mathrm{q}}$ & months & 4 & 24 & 12 & Runoff time scale \\
$\alpha$ & - & 0 & 0.5 & 0.2 & Interception \\
$s_{\mathrm{m}}$ & $\mathrm{mm}$ & 0 & 1000 & 300 & Max. soil moisture \\
$\xi_{s}$ & $\mathrm{~mm} \mathrm{months}^{-1}$ & -300 & 300 & 10 & Rate of soil moisture change \\
$E_{\mathrm{pm}}$ & $\mathrm{mm} \mathrm{year}^{-1}$ & 100 & 2400 & 1200 & Max. annual potential evaporation \\
$e_{\mathrm{m}}$ & $\mathrm{mm}_{I}$ & $f\left(\tau_{\mathrm{e}}, E_{\mathrm{pm}}\right)$ & $f\left(\tau_{\mathrm{e}}, E_{\mathrm{pm}}\right)$ & 100 & Max. evaporable water \\
$u_{x}$ & $\left.\mathrm{month}^{-1}\right]$ & -10 & 10 & 1.2 & Lateral convergence \\
$c_{\mathrm{m}}$ & $\mathrm{mm}^{-1}$ & 0.5 & 10 & 5 & Wind speed \\
\hline
\end{tabular}

Table 3. Parameter values of the examples of Fig. 4 and corresponding equilibrium moisture $W_{1}$ and maximum soil moisture max $(S)$ for two different values of $\xi_{s}$ (for $\xi_{s}=10 \mathrm{~mm} \mathrm{month}^{-1}$, one of the parameter sets leads to a negative $\max (S)$, i.e. this parameter set is physically not possible); units and other parameter values as in Table 2.

\begin{tabular}{lrrrrr}
\hline Parameter & Reference & $\begin{array}{r}\text { Low } \\
\text { convergence }\end{array}$ & $\begin{array}{r}\text { Fast } \\
\text { precipitation }\end{array}$ & $\begin{array}{r}\text { Slow } \\
\text { evaporation }\end{array}$ & $\begin{array}{r}\text { Fast } \\
\text { evaporation }\end{array}$ \\
\hline$I$ & 1.2 & 0.3 & 1.2 & 1.2 & 1.2 \\
$\tau_{\mathrm{p}}$ & 10 & 10 & 5 & 10 & 10 \\
$\tau_{\mathrm{e}}$ & 3 & 3 & 3 & 6 & 1 \\
$W_{1}$ for $\xi_{s}=0$ & 0.8 & 0.5 & 0.6 & 0.8 & 0.9 \\
$W_{1}$ for $\xi_{s}=10$ & 0.8 & 0.2 & 0.6 & 0.7 & 0.8 \\
$\max (S)$ for $\xi_{s}=0$ & 288 & 72 & 288 & 288 & 287 \\
$\max (S)$ for $\xi_{s}=10$ & 168 & -48 & 168 & 167 & 168 \\
\hline
\end{tabular}

For soil moisture storage $S$, the effect depends on the location along $x$ : $S$ decreases close to the coast and increases inland; this is illustrated in Fig. $5 \mathrm{c}$, which shows the runoff profile along $x$ (and thus also the form of the soil moisture profile that is linearly related to the runoff profile). The related evaporation increase shows a maximum at a certain distance from the coast. Of course, such a simplistic analysis of a potential climate change impacts has to be handled with care since a temperature modification will simultaneously affect many other parameters and most notably $c_{\mathrm{m}}, e_{\mathrm{m}}$ and $\tau_{\mathrm{p}}$.

\subsection{Regime switches}

A given hydroclimatologic parameter set $\Theta$ corresponds to a particular moisture profile (in the atmosphere and in the soil) that is characterized by the length scale $L$ and the equilibrium moisture $W_{1}$. If the parameters change to a new value at a given point $x^{\prime}$ of the trajectory, this can first of all modify $L$, which only modifies the characteristic length scale of the profile but not its shape. The effect of a parameter modification on $W_{1}$ can create three different situations in an increasing regime:
1. if $W\left(x^{\prime} \mid \Theta\right)<W_{1}\left(\Theta^{\prime}\right)<W_{1}(\Theta)$, the rate of moisture increase slows down;

2. if $W_{1}\left(\Theta^{\prime}\right)>W_{1}(\Theta)$, the rate of increase accelerates;

3. if $W\left(x^{\prime} \mid \Theta\right)>W_{1}\left(\Theta^{\prime}\right)$, the moisture starts decreasing in $x^{\prime}$.

We call this last situation, where the slope of the moisture profile changes sign, a regime switch. For the decreasing regime, a regime switch occurs if $W\left(x^{\prime} \mid \Theta\right)<W_{1}\left(\Theta^{\prime}\right)$.

In mathematical terms, if the parameter set $\Theta$ is modified to $\Theta^{\prime}$ at a given point $x^{\prime}$, a regime switch occurs in $x^{\prime}$ if and only if it holds

$\left.\left[W_{1}\left(\Theta^{\prime}\right)-W\left(x^{\prime} \mid \Theta\right)\right] \frac{\mathrm{d} W(x \mid \Theta)}{\mathrm{d} x}\right|_{x=x^{\prime}}>0$.

The susceptibility for a regime change, thus, depends on $W(x)$ and on the sensitivity of $W_{1}$ with respect to a parameter change. Since there is no explicit solution $W(x)$ of Eq. (17), a qualitative analysis of this susceptibility has to be completed for individual parameter sets.

In nature, a sudden variation of the hydrometerological parameters can occur due to land use (e.g. large wetlands) and 

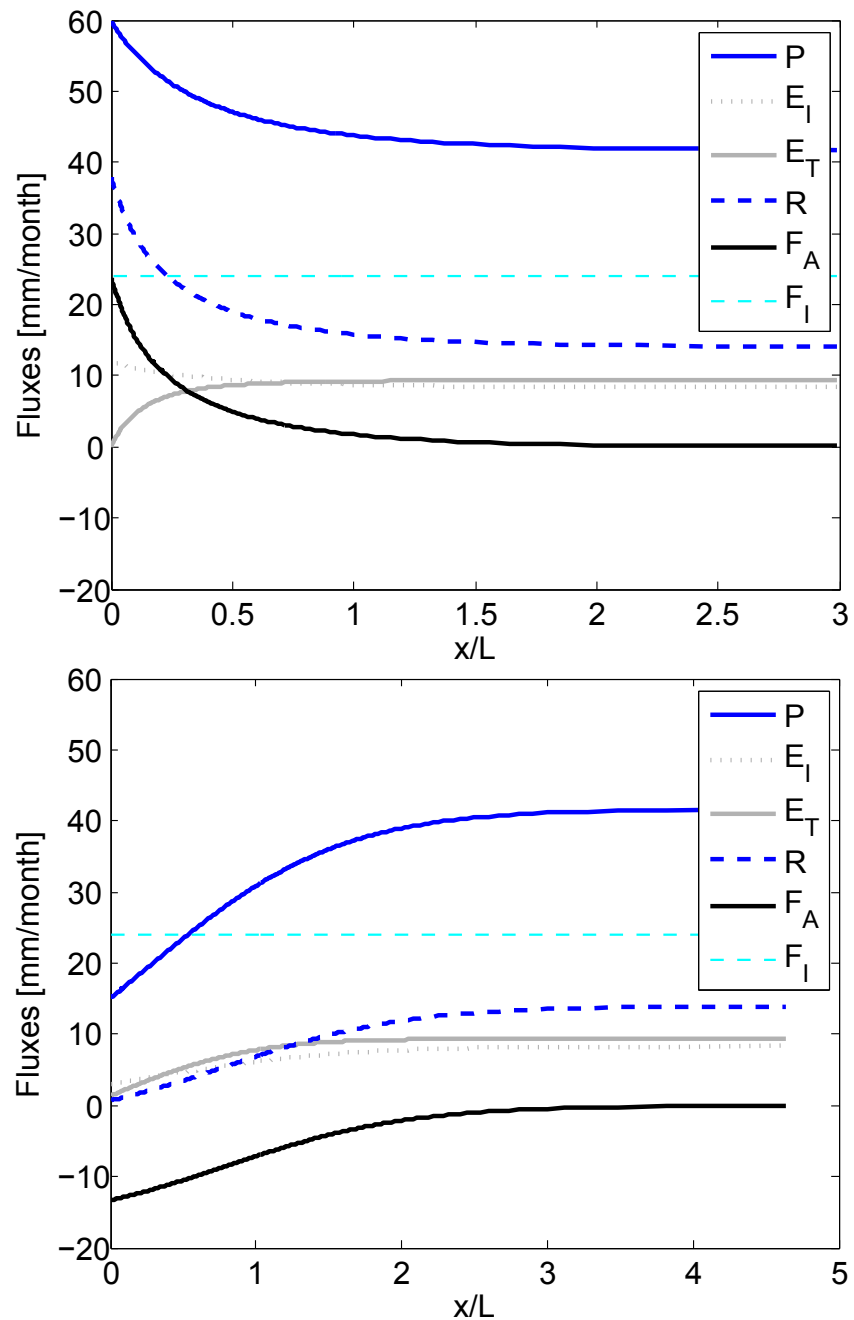

Fig. 3. Top: Point scale fluxes along $x$ corresponding to the two regimes of Fig. 2; top; $W_{0}=1.0$, bottom: $W_{0}=0.5 ; F_{\mathrm{a}}$ stands for the advective flux, $F_{I}$ for the lateral influx. Note that for $W_{0}=1.0$, $E_{\mathrm{T}}=0$, see Eq. (3).

topography. Mountain ridges can decrease the water holding capacity of the atmosphere or the precipitation time scale, they can induce very different evaporation time scales, or modify lateral convergence. Spatial gradients of climatological convergence also typically exist in the North American system (Higgins et al., 1997).

Particularly interesting are potential regime switches due to land use changes. A common question is to anticipate the impact of a modification of the evaporation process on runoff. Considering the feedback system rather than the isolated hydrologic system suggests that the expected response depends on the moisture regime and on the lateral convergence. For example, a decrease of interception could cause a regime switch further downstream if an increasing moisture regime is dominating close to the coast (Fig. 6 top). An increase of the evaporation time scale $\tau_{\mathrm{e}}$ could either slow
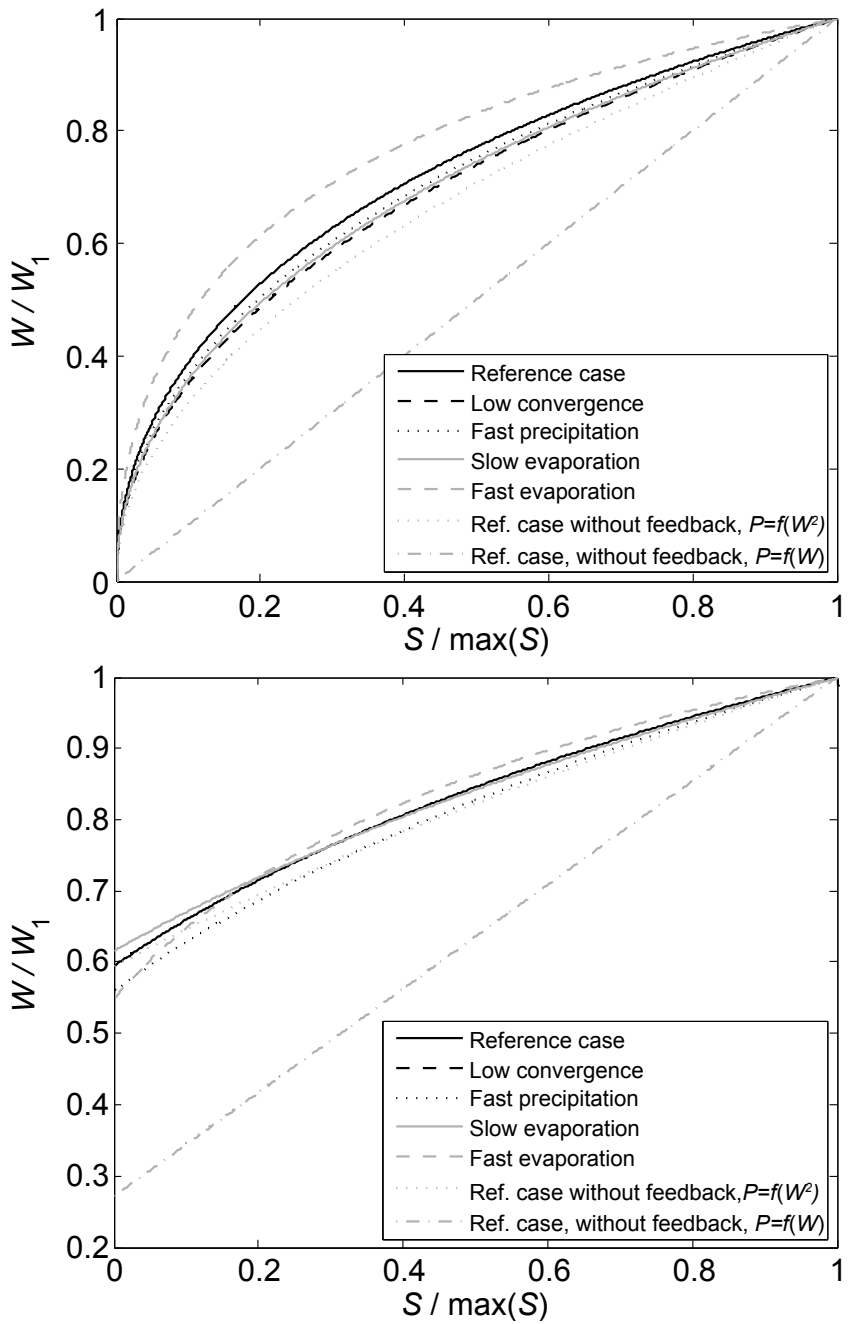

Fig. 4. Relative atmospheric moisture plotted against relative soil moisture filling for the reference case of Table 2 and 4 additional cases (see Table 3), top: for $\xi_{s}=0$, bottom: for $\xi_{s}=10 \mathrm{~mm}$ month $^{-1}$ (note the different y-axis scale). The last two cases correspond to a model without the coupling term (1-W) in Eq. (13) and with $P$ given as a linear function of $W$.

down the increasing regime or lead to a regime switch, depending on the values of all other parameter values and on the location of the land use change (see Fig. 6, bottom, where a modification of $\tau_{\mathrm{e}}$ in two different locations is illustrated).

\subsection{The role of interception}

For given climatic parameters $I$ and $\tau_{\mathrm{p}}$, an increase in interception always leads to an increase of the atmospheric equilibrium moisture $\left(\mathrm{d} W_{1} / \mathrm{d} \alpha>0 \forall \Theta\right)$. Accordingly, in the decreasing regime, even a small increase of $\alpha$ can cause a regime switch. A regime switch induced by a change in $\alpha$ is illustrated in Fig. 6.

Furthermore, an increase of $\alpha$ leads to a decrease of soil moisture at any location $x(\mathrm{~d} S / \mathrm{d} \alpha<0 \forall \Theta)$. This results in a 

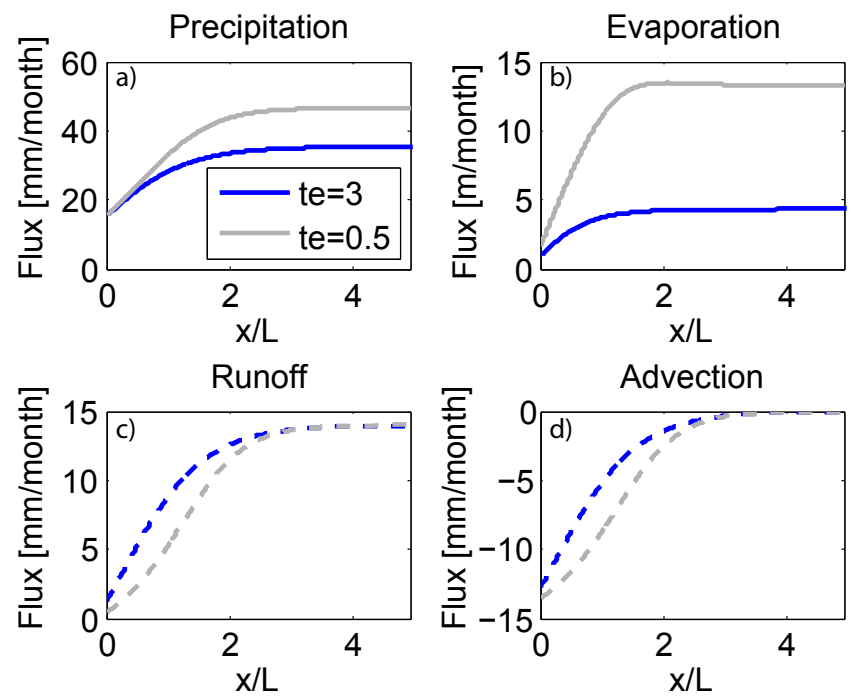

Fig. 5. Effect of faster evaporation on fluxes (default parameter values with $W_{0}=0.5$ and $s_{\mathrm{m}}=200 \mathrm{~mm}$ ). Note the different $\mathrm{y}$-scale for precipitation and the negative scale for advection.

decreased runoff coefficient $c_{R}$ defined as

$c_{R}=\frac{R}{P}$.

Using Eq. (8), Eq. (9) and substituting $\frac{S}{c_{\mathrm{m}}}$ with Eq. (16) shows the direct relationship between the interception parameter $\alpha$ and $c_{R}$ :

$c_{R}=\frac{1-\alpha}{1+\kappa(1-W)}\left(1-\frac{D^{*}}{W^{2}}\right)$.

If we consider the runoff coefficient for an entire year $\overline{c_{R}}=$ $c_{R}\left(\xi_{s}=0\right)$, it can easily be seen that $\frac{\mathrm{d} \overline{c_{R}}}{\mathrm{~d} \alpha}<0 \forall \Theta$, i.e. any increase of interception will decrease the runoff coefficient. Interception also determines the length scale of the feedback system $L$, which increases for increasing $\alpha$, implying that for higher $\alpha$, the equilibrium moisture is reached further inland.

Given the joint effect of $\alpha$ on $L$ and the equilibrium moisture, it can also be shown (Eq. 16) that for a higher $\alpha$, the same relative moisture is reached at a shorter distance inland in an increasing regime, and at a longer distance inland for a decreasing regime. This results in both cases in an increasing atmospheric moisture at a given location $x$ for a higher $\alpha$. This simply translates the fact that with increasing interception, the net water flux from the atmosphere to the soil, $P-E_{\mathrm{I}}$, decreases.

\subsection{Horton index}

From a hydrological point of view, the system can be characterized by the so-called Horton index (see, e.g. Troch et al., 2009), defined as the ratio between the average amount of water leaving the hydrologic system (i.e. the
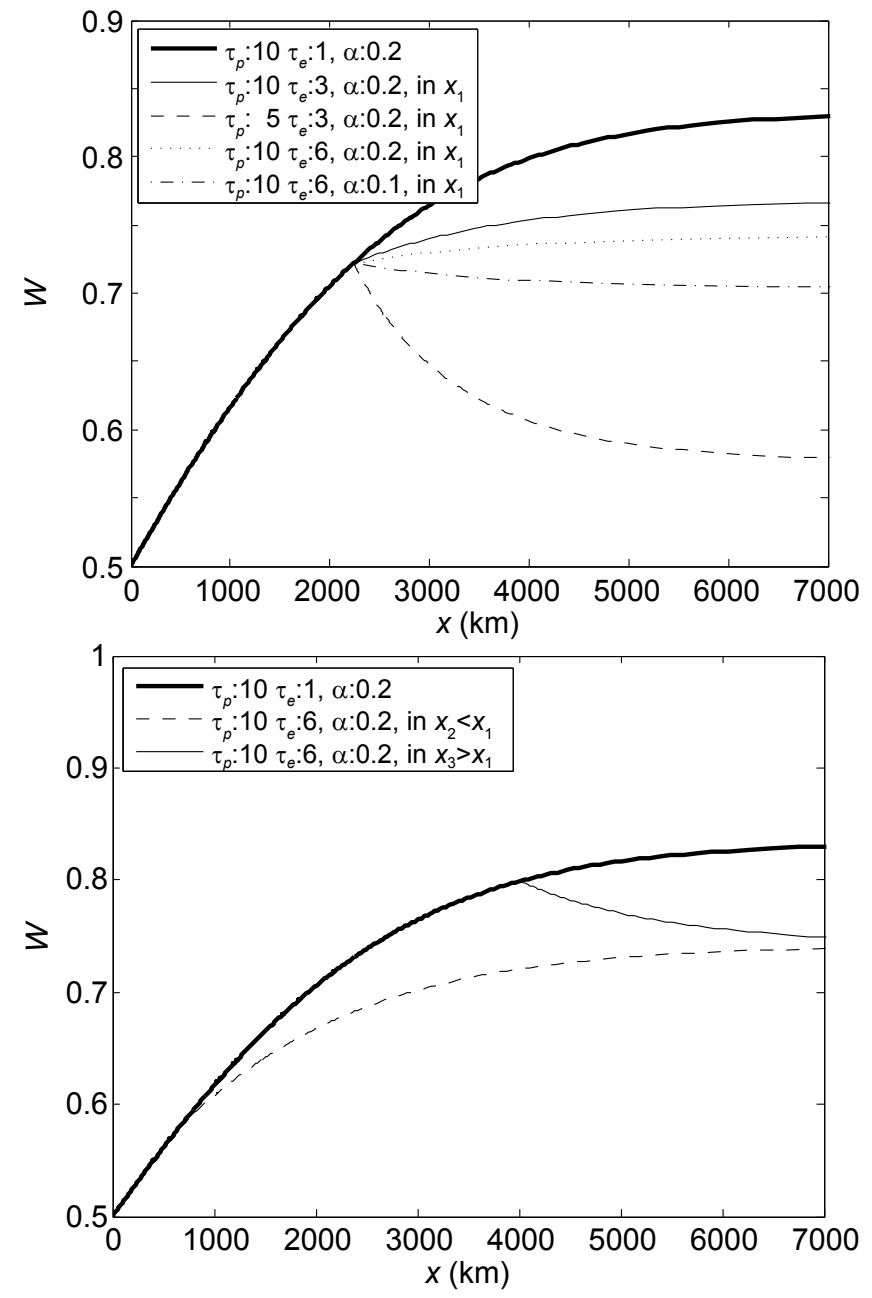

Fig. 6. Moisture profile modifications and regimes switches due to parameter changes (parameter units as in Table 2), top: for changes of $\tau_{\mathrm{p}}, \tau_{\mathrm{e}}, \alpha$ in $x_{1}$, bottom for a change of $\tau_{\mathrm{e}}$ in two different locations $x_{2}<x_{1}$ and $x_{3}>x_{1}$; note the role of $\alpha$ in the switch induced with the parameter set $\tau_{\mathrm{p}}=10$ days, $\tau_{\mathrm{e}}=6$ months (top figure).

soil) through evaporation and total water entering the soil compartment, i.e.

$H=\frac{E_{\mathrm{T}}}{P-E_{\mathrm{I}}}$.

Replacing $P$ with Eq. (9), $E_{\mathrm{T}}$ with Eq. (13), $E_{\mathrm{I}}$ with Eq. (10) and substituting $S / c_{\mathrm{m}}$ with Eq. (16) yields

$H=\frac{\kappa(1-W)}{1+\kappa(1-W)}\left(1-\frac{D^{*}}{W^{2}}\right)$.

The Horton index is often estimated with meteorological quantities averaged over yearly time steps, where it is assumed that $\xi_{s}\left(t_{y r}\right)=0$; making the same assumption here, i.e. $\bar{H}=H\left(\xi_{s}=0\right)$, yields

$\bar{H}=\frac{\kappa(1-W)}{1+\kappa(1-W)}$. 


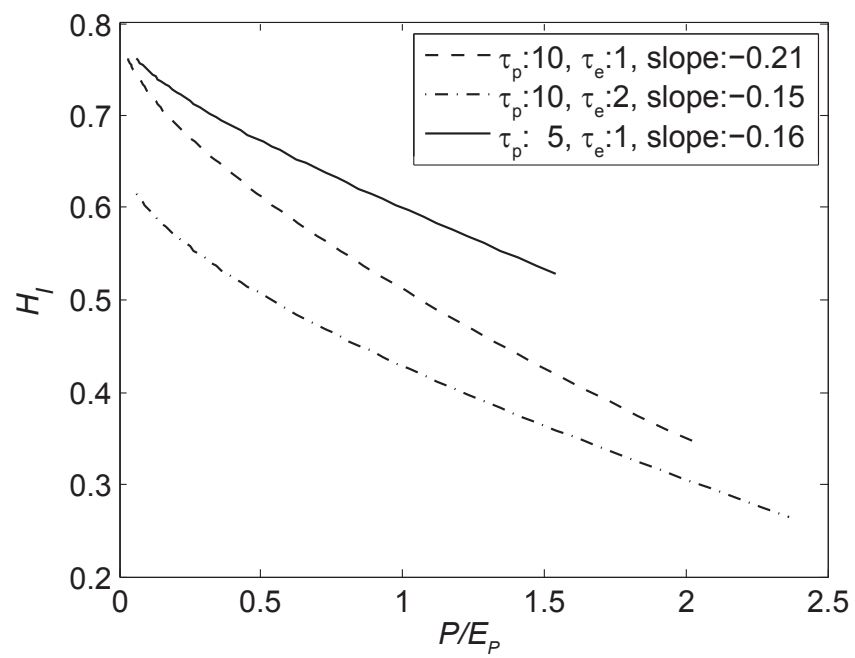

Fig. 7. Horton index $\bar{H}$ as a function of humidity index $P / E_{\mathrm{P}}$ computed for $W \in[0.2,1]$; for each parameter set, only part of the humidity index domain is covered by the possible model outcomes.

This relationship only depends on the parameters of the hydrologic system $\left(s_{\mathrm{m}}, \tau_{\mathrm{p}}, \tau_{\mathrm{e}}\right)$ and the climatic parameter $e_{\mathrm{m}}$, i.e. the analytic relationship between $H$ and $W$ does not depend on the chosen relationship between $P$ and $W$ (because $P$ cancels out from the equation). It summarizes the assumptions about $E_{\mathrm{T}}(S, W)$ and $R(S)$. For the increasing moisture regime, the Horton index is decreasing inland; for the decreasing moisture regime, the Horton index is increasing.

$\bar{H}$ is an increasing function of $(1-W)$ and has the form of the the well-known Langmuir equation (Langmuir, 1916) that expresses the equilibrium between adsorption to a solid surface and the concentration in the surrounding medium, with a constant corresponding to the ratio between rate of adsorption and desorption. This analogy is interesting: the relative outflux from the soil surface (i.e. $\bar{H}$ ) is a function of available storage in the atmosphere $(1-W)$. The shape of this function is given by the ratio $\kappa$ of maximum evaporation to maximum runoff. $\bar{H}$ has the limit $\bar{H}(W \rightarrow 0)=\kappa(1+\kappa)^{-1}$, which corresponds to the relationship that we would obtain if there was no feedback term $(1-W)$ in Eq. (13).

In a recent empirical study, Troch et al. (2009) suggested that the Horton index could be some linear decreasing function of the humidity index, the ratio between annual precipitation and potential evaporation. For plausible parameter values, our analytical model reproduces this almost linear relationship (Fig. 7), with slopes very similar to the ones found by Troch et al. (2009). Voepel et al. (2011), on the other hand, found a power-law-like relationship between the Horton index and the aridity index $\phi$, the inverse of the humidity index. For our model, $\phi$ equals:

$\phi=\frac{E_{\mathrm{P}}+E_{\mathrm{I}}}{P}=\frac{s_{\mathrm{m}} \tau_{\mathrm{p}}}{c_{\mathrm{m}} \tau_{\mathrm{q}}} \frac{\kappa(1-W)}{W^{2}}+\alpha$, where $E_{\mathrm{P}}+E_{\mathrm{I}}$ corresponds to the total potential evaporation (see the comment on Eq. 12).

Expressing $\kappa(1-W)$ as a function of $H$, Eq. (38), and as a function of $\phi$, Eq. (39), we find

$\phi=\alpha+\frac{H}{\psi(1-H)}$,

where $\psi=\frac{\tau_{\mathrm{q}}}{s_{\mathrm{m}}} \frac{c_{\mathrm{m}} W^{2}}{\tau_{\mathrm{p}}}$ represents the ratio of precipitation to maximum runoff. This relationship represents well the type of relationship found by Voepel et al. (2011) (see their Fig. 3c; note that they did not consider interception losses in their analysis). As postulated by Voepel et al. (2011), it summarizes how the climate interacts with landscape properties.

\subsection{Budyko curve}

Closely related to the Horton index, but more well-known, is the Budyko curve (Budyko, 1984; Gerrits et al., 2009), relating the ratio of annual evaporation to annual precipitation to the aridity index. Following the same derivation as for the Horton index, we obtain for $B_{\mathrm{u}}=E / P$ :

$B_{\mathrm{u}}=\frac{E}{P}=\frac{\alpha+\kappa(1-W)}{1+\kappa(1-W)}$,

with $E=E_{\mathrm{T}}+E_{\mathrm{I}}$.

Expressing $\kappa(1-W)$ as a function of $B_{\mathrm{u}}$ and as a function of $\phi$, we find

$B_{\mathrm{u}}=1-\frac{1-\alpha}{1+\psi(\phi-\alpha)}$.

The equation gives a reasonable approximation of the relationships proposed by previous authors (see a collection in Gerrits et al., 2009) and namely of the simplest model, $B_{\mathrm{u}}=1-\exp (-\phi)$, proposed by Schreiber (1904). It has the main advantage of explicitly highlighting the role of interception. Note, however, that the model only holds for $\phi>\alpha$ and that certain parameter values lead to non-physical solutions.

\subsection{Recycling ratio}

A fundamental property of the hydroclimatic feedback system is the recycling of water originally evaporated over the ocean through multiple cycles of evaporation and precipitation over the continent along a moisture trajectory (e.g. Dirmeyer et al., 2009; Van der Ent et al., 2010; Worden et al., 2007). So-called recycling ratios are used as indicators of how important moisture recycling is to sustain rainfall at a given location.

There are different methods to characterize this recycling (see Van der Ent et al., 2010, for a discussion); we retain here the scale-independent formulation of precipitation recycling $\rho(x)$ as a function of the distance $x$ traveled along a trajectory proposed by van der Ent and Savenije (2011) based on the work of Dominguez et al. (2006): 


$$
\begin{aligned}
\rho(x) & =1-\exp \left(-\int_{x_{0}}^{x} \frac{E\left(x^{\prime}\right)}{C\left(x^{\prime}\right) u_{x}} \mathrm{~d} x^{\prime}\right) \\
& =1-\exp \left(-\frac{x}{\lambda(x)}\right),
\end{aligned}
$$

where $E$ is the total evaporation. $\lambda(x)$ is the length scale of precipitation recycling, which is a measure of the distance over which evaporated water is removed from the atmosphere through precipitation and which characterizes the process.

It holds that $\frac{\mathrm{d} \rho}{\mathrm{d} x}>0$ and $\rho(x \rightarrow \infty)=1$.

In the above formulation, $\rho(x)$ is the recycling ratio defined in $x$, whereas $\lambda(x)$ is an integrated value over $x_{0} \rightarrow x$. Accordingly, there is no analytical expression for $\lambda(x)$, and $\rho(x)$ can only be approximated numerically. Using the discretization $x_{i}=x_{i-1}+\delta_{x}$, we re-write

$$
\begin{aligned}
\rho\left(x_{i}, \lambda_{i}\right) & =1-\exp \left(-\frac{x_{i}}{\lambda\left(x_{i}\right)}\right) \\
& =1-\exp \left(-\frac{x_{i-1}+\delta_{x}}{\lambda\left(x_{i-1}+\delta_{x}\right)}\right) .
\end{aligned}
$$

Given that $\lambda$ varies gradually along $x$, we assume that $\lambda\left(x_{i-1}+\delta_{x}\right) \simeq \lambda\left(x_{i-1}\right)=\lambda_{i-1}$. The above can then be decomposed as follows:

$$
\begin{aligned}
\rho\left(x_{i}, \lambda_{i}\right) & \simeq 1-\exp \left(-\frac{x_{i-1}+\delta_{x}}{\lambda_{i-1}}\right) \\
& =1-\exp \left(-\frac{x_{i-1}}{\lambda_{i-1}}\right) \exp \left(-\frac{\delta_{x}}{\lambda_{i-1}}\right) \\
& =1-\exp \left(-\frac{x_{i-1}}{\lambda_{i-1}}\right)\left[1-\rho\left(\delta_{x}, \lambda_{i-1}\right)\right] \\
& =1-\exp \left(-\frac{x_{i-1}}{\lambda_{i-1}}\right)+\exp \left(-\frac{x_{i-1}}{\lambda_{i-1}}\right) \rho\left(\delta_{x}, \lambda_{i-1}\right) \\
& =\rho\left(x_{i-1}\right)+\left[1-\rho\left(x_{i-1}\right)\right] \rho\left(\delta_{x}, \lambda_{i-1}\right) .
\end{aligned}
$$

The last term of the above expression can be estimated following van der Ent and Savenije (2011), who showed that, choosing a sufficiently fine discretisation, the recycling length scale $\lambda_{\delta x}=\lambda\left(\delta_{x}\right)$ can be approximated as

$\lambda\left(\delta_{x}\right)=u_{x} \frac{\bar{C}\left(x_{i-1}, x_{i}\right)}{\bar{E}\left(x_{i-1}, x_{i}\right)}=u_{x} c_{\mathrm{m}} \frac{\bar{W}\left(x_{i-1}, x_{i}\right)}{\bar{E}\left(x_{i-1}, x_{i}\right)}$,

where $\bar{E}\left(x_{i-1}, x_{i}\right)$ is the average total evaporation in the interval $\left[x_{i-1}, x_{i}\right]$.

Using Eq. (46) and assuming $\rho\left(\delta_{x}, \lambda_{i-1}\right) \simeq \rho\left(\delta_{x}, \lambda_{\delta x}\right)$, we can iteratively compute $\rho\left(x_{i}, \lambda_{i}\right)$ with Eq. (45), starting in $x=0$. An example is illustrated in Fig. 8 for the default parameter values and the increasing and the decreasing regime. Since the trajectory starts at the coast, $\rho\left(x_{i}, \lambda_{i}\right)$ gives an estimate of continental precipitation recycling (Van der Ent et al., 2010).

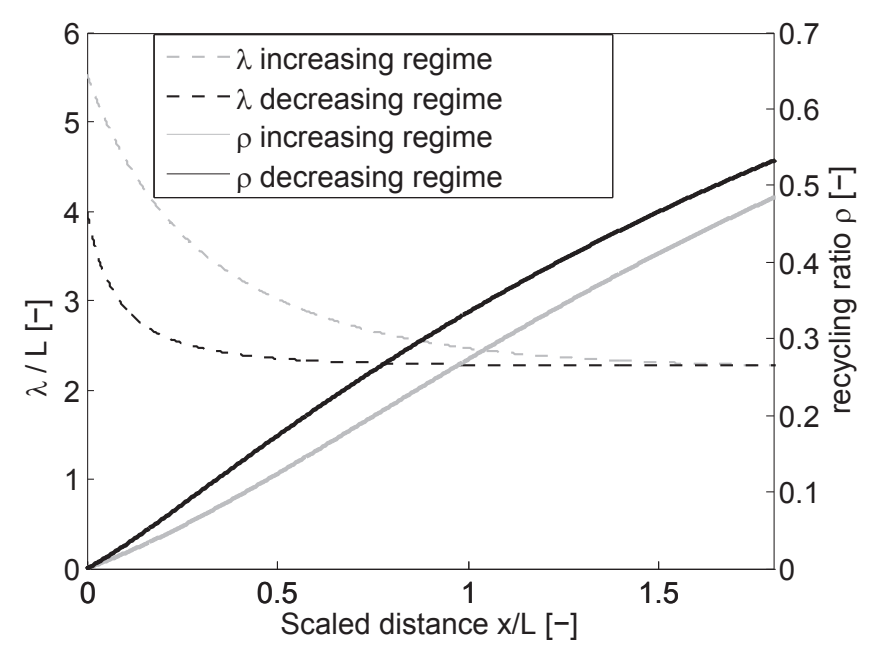

Fig. 8. Continental recycling ratio and recycling length scale $\lambda(\delta x)$ (computed according to Eq. 46 relative to the moisture regime length scale $L)$ along $x$ for the two regimes of Fig. $2\left(W_{0}=0.5\right.$ resp. $\left.W_{0}=1.0, W_{1}=0.83, L=5400 \mathrm{~km}\right)$ with $\delta_{x}=5 \mathrm{~km}$.

This figure illustrates that the shape of the recycling profile along $x$ has a more complicated shape than what could have been expected from Eq. (43); this results from how $E$ and $C$ vary along $x$ and explains why the above discretisation is necessary.

Considering an entire year $\left(\xi_{s}=0\right)$ and assuming $\bar{W}\left(x_{i-1}, x_{i}\right) \simeq W\left(x_{i}\right)$ and $\bar{E}\left(x_{i-1}, x_{i}\right) \simeq E\left(x_{i}\right)=E_{\mathrm{T}}\left(x_{i}\right)+$ $E_{\mathrm{I}}\left(x_{i}\right)$, we can further analyze the behaviour of $\lambda\left(\delta_{x}\right)$ as a function of the model parameters:

$$
\begin{aligned}
\lambda\left(\delta_{x}\right) & \simeq u_{x} c_{\mathrm{m}} \frac{W\left(x_{i}\right)}{E_{\mathrm{T}}\left(x_{i}\right)+E_{\mathrm{I}}\left(x_{i}\right)} \\
& =u_{x} \tau_{\mathrm{p}} \frac{1}{W\left(x_{i}\right)} \frac{1+\kappa\left(1-W\left(x_{i}\right)\right)}{\alpha+\kappa\left(1-W\left(x_{i}\right)\right)} \\
& =u_{x} \tau_{\mathrm{p}} \frac{1}{W\left(x_{i}\right)} \frac{1}{B_{\mathrm{u}}\left(x_{i}\right)},
\end{aligned}
$$

where the middle equality is obtained in two steps: (i) replacing $E_{\mathrm{I}}$ with Eq. (9) combined to Eq. (10) and $E_{\mathrm{T}}$ with Eq. (13), (ii) isolating $S / c_{\mathrm{m}}$ and replacing it with Eq. (16).

As expected, the wind speed directly influences the recycling length scale; the a priori not expected (Goessling and Reick , 2011) direct effect of the precipitation time scale $\tau_{\mathrm{p}}$ results from the moisture compartment coupling and the effect of $\tau_{\mathrm{p}}$ on $W$ and on $S$. The effect of these two parameters is modulated by a factor depending on $W, \alpha$ and $\kappa$, just as the length scale of the moisture regime, $L=\frac{u_{x} \tau_{\mathrm{p}}}{1-\alpha}$, is modulated by a factor depending only on interception. $L$ is longer than $\lambda$ for high values of $W$ and of $\alpha$. Equation (47) also shows that if the Budyko value $B_{\mathrm{u}}$ increases (i.e. for increasing aridity), the recycling length scale decreases. 


\section{Discussion}

We presented an analytical, coupled model of the moisture fluxes between the soil and the atmosphere. This feedback model has the potential to give insights into nonlinear moisture recycling mechanisms that sustain rainfall along dominant moisture trajectories at continental scales $(>500 \mathrm{~km})$, at which the rainfall sustaining effect of recycling represents an important aspect of soil-atmosphere moisture coupling. The model can distinguish between interception (fast feedback of moisture) and delayed feedback through the soil by way of transpiration and soil evaporation, which are two major advantages over existing analytical approaches that only consider the atmospheric moisture explicitly and make simplifying assumptions about fluxes that depend on the soil moisture (Bierkens and van den Hurk, 2007; Savenije, 1995a, 1996).

Before briefly exposing potential applications of the model, we hereafter discuss some obvious limitations related to the underlying assumptions. First of all, the presented solution to the coupled moisture equations assumes that all parameters are constant in time and in space. To study the behaviour of a particular system, this assumption might be relaxed by discretizing the moisture trajectory into portions with constant parameter values.

Another strong assumption is the completely mixed atmosphere. It follows that the model cannot be used to study strongly layered systems where the origin of moisture depends on the height in the atmosphere. This is for example the case for the West-African monsoon system that develops at the confluence of low-level moist southwesterly winds and higher-level dry northeasterly winds (Sultan and Janicot, 2003). Ongoing research with the moisture tracking model of Van der Ent et al. (2010) suggests that assuming a 2-layers atmospheric system significantly improves the moisture tracking results. In an analytical model, however, the parameterization of such a layered system and of the exchange fluxes between the layers is far from being trivial.

For the parameterization of the soil moisture compartment, the constant rate of soil moisture change, $\xi_{s}$, might appear as being utmost limiting. As previously mentioned, a constant $\xi_{s}$ per season describes well the seasonal (i.e. low frequency) dynamics of soil moisture at many places but might not be adapted to places where high frequency dynamics dominate (i.e. extremely dry or wet places). The assumption that all water infiltrates into the soil further restricts the use of the model to environments where direct runoff is not an important component of the water balance. The model also neglects any evaporation-sustaining effect of large groundwater reservoirs, which might play a role during the dry season in wet-to-dry climate transition zones (Bierkens and van den Hurk, 2007).

Keeping the above limitations in mind, we see three types of applications of the analytical framework. First of all, the resulting nonlinear relationship between soil and atmospheric moisture can explain why there is no simple answer to questions of the type "what happens if rainfall increases?". We presented only a generic example but we anticipate that a detailed analysis for seasonally dominant moisture trajectories on different continents could give valuable indications on how different the effect of climate or land use changes can be in regions that play a crucial role for moisture recycling, especially in regions that are moisture suppliers during a part of the year (Koster et al., 2004; Van der Ent et al., 2010).

Furthermore, the analytic framework reveals how the different parameter values could influence the seasonal moisture regimes and what types of parameter modifications could create regime switches. Such a regime switch at a given location would cause a major modification of the hydrologic cycle further downstream, possibly resulting from some minor change of process time scales (e.g. due to vegetation change) if this change extends over a significant scale.

In summary, the presented model is designed to study how the influence of (land-use) changes propagates downwind on the continental scale (on weekly to monthly time scales), i.e. where the spatially integrated evaporation along a moisture trajectory reaches the same order of magnitude as the advective flux. The value of such an analysis is to complement the various modelling studies that analyze the influence of land use changes on the circulation. This suggests that studies that analyze and try to anticipate climate or land use changes (Pitman et al., 2009) could profit from a preliminary analysis of the relationship between $W$ and $S$ along the dominant trajectory for dry and wet seasons, focusing on: (1) the moisture regime (decreasing or increasing inland), (2) how close the actual processes are to a potential regime switch, and (3) which system characteristics could cause it. As discussed for interception, such a preliminary analysis could, e.g. show that even a parameter with a priori minor importance could be decisive for a regime switch. A next step would be to analyze the dynamics of the system, to show, e.g. how long it takes for a step change in moisture at the coast to propagate to some distance inland, but this is left for future research.

Finally, the analytic framework could also be useful to quantify hydrologic similarity. Such an analysis aims at understanding how the basic hydrologic functions "partitioning", "storage" and "release" of water (see Wagener et al., 2007) are related to physiographic characteristics and climate, especially for the prediction of future hydrologic behaviour. An example of how to make use, hereby, of purely analytical tools is the work of Woods (2009), who presented an analytic seasonal snow cover model to understand the interplay of the temperature regime, meteorological seasonality and precipitation rates.

For the present analytical model, the Horton index shows nicely what we can gain from analytical modelling of soil and atmospheric moisture for understanding hydrologic similarity: potential relationships between how the hydrologic system partitions water between runoff and evaporation and climate are not "blurred" by some exogenous forcing of which we do not know how representative they are for the behaviour 
of the system. The precipitation recycling ratio has been derived for the same purpose of understanding how different time scales "conspire" to increase or decrease moisture recycling along a trajectory.

\section{Conclusions}

We presented a feedback model of the moisture fluxes between the soil and the atmosphere and derived its analytical solutions, yielding functional relationships between moisture profiles along a dominant trajectory starting at the coast and hydroclimatic parameters. The key features of the model are the nonlinear coupling between the atmospheric and the soil moisture stores resulting from the functional dependance of evaporation on both moisture storages and the separate treatment of soil evaporation (mostly through transpiration) and evaporation from intercepted water. The model considers only water fluxes; energy constraints are incorporated in the form of parameters in the potential evaporation formulation.

This analytical model, although it might be qualified as a "toy model" given the overwhelming complexity of underlying natural processes, allows first order analyses of the nonlinear relationship between the states of soil moisture and of atmospheric moisture as a function of process parameters characterizing a given hydroclimatic behaviour, in particular the time scales of evaporative fluxes, precipitation and runoff, but independent of observed meteorological time series. For hydrology, this represents a perspective change: precipitation and potential evaporation are no longer exogenous forcing variables. Hydrologic behaviour and its sensitivity to changes can be analyzed in terms of local moisture exchanges as well as upstream climate or moisture regimes.

While we presented only generic examples here, we hope that the analytical framework will be of use in future work to explore the range of potential impacts of climate and land use change on different continents. We also look forward to an expansion of the framework to include feedback between state variables and the time scale of dominant processes (e.g. soil wetness on precipitation), to explicitly account for topographic or temperature effects (e.g. through a variation of the atmospheric water holding capacity) or to include surface runoff.

\section{Supplementary material related to this article is available online at: http://www.hydrol-earth-syst-sci.net/ 16/1863/2012/hess-16-1863-2012-supplement.pdf.}

Acknowledgements. The research of the first author was supported by a research grant of the Swiss National Science Foundation (SNF, PZ00P2_126607). The second author was supported by the Division for Earth and Life Sciences (ALW) with financial aid from the Netherlands Organization for Scientific Research (NWO). We also would like to thank the three reviewers and the
Editor B. van den Hurk for their careful review of our manuscript and the fruitful public discussion (available online), in particular H. Goessling, whose comments significantly improved the quality and the readability of our manuscript.

Edited by: B. van den Hurk

\section{References}

Bierkens, M. P. and van den Hurk, B. J. J. M.: Groundwater convergence as a possible mechanism for multi-year persistence in rainfall, Geophys. Res. Lett., 34, L02402, doi:10.1029/2006GL028396, 2007.

Bretherton, C. S., Peters, M. E., and Back, L. E.: Relationships between water vapor path and precipitation over the tropical oceans, J. Climate, 17, 1517-1528, doi:10.1175/15200442(2004)017<1517:rbwvpa > 2.0.co;2, 2004.

Brutsaert, W.: Hydrology, an introduction, Cambridge Univeristy Press, Cambridge, 2005.

Budyko, M. I.: Evaporation Under Natural Conditions, Gidrometeorizdat, St. Petersburg, Russia, 1984.

Burde, G. I. and Zangvil, A.: The estimation of regional precipitation recycling, Part I: Review of recycling models, J. Climate, 14, 2497-2508, doi:10.1175/15200442(2001)014<2497:TEORPR>2.0.CO;2, 2001.

Clark, M. P., Slater, A. G., Rupp, D. E., Woods, R. A., Vrugt, J. A., Gupta, H. V., Wagener, T., and Hay, L. E.: Framework for Understanding Structural Errors (FUSE): A modular framework to diagnose differences between hydrological models, Water Resour. Res., 44, W00b02, doi:10.1029/2007wr006735, 2008.

DeAngelis, A., Dominguez, F., Fan, Y., Robock, A., Kustu, M. D., and Robinson, D.: Evidence of enhanced precipitation due to irrigation over the Great Plains of the United States, J. Geophys. Res., 115, D15115, doi:10.1029/2010JD013892, 2010.

de Groen, M. M. and Savenije, H. H. G.: A monthly interception equation based on the statistical characteristics of daily rainfall, Water Resour. Res., 42, W12417, doi:10.1029/2006WR005013, 2006.

Dirmeyer, P. A., Koster, R. D., and Guo, Z. C.: Do global models properly represent the feedback between land and atmosphere?, J. Hydrometeorol., 7, 1177-1198, doi:10.1175/JHM532.1, 2006.

Dirmeyer, P. A., Brubaker, K. L., and DelSole, T.: Import and export of atmospheric water vapor between nations, J. Hydrol., 365, 1122, doi:10.1016/j.jhydrol.2008.11.016, 2009.

Dominguez, F. and Kumar, P.: Precipitation Recycling Variability and Ecoclimatological Stability - A Study Using NARR Data, Part II: North American Monsoon Region, J. Climate, 21, 51655186, doi:10.1175/2008JCLI1760.1, 2008.

Dominguez, F., Kumar, P., Liang, X. Z., and Ting, M. F.: Impact of atmospheric moisture storage on precipitation recycling, J. Climate, 19, 1513-1530, doi:10.1175/JCLI3691.1, 2006.

Eltahir, E. A. B.: A soil moisture-rainfall feedback mechanism. 1. Theory and observations, Water Resour. Res., 34, 765-776, doi:10.1029/97WR03499, 1998.

Eltahir, E. A. B. and Bras, R. L.: Precipitation recycling in the Amazon Basin, Q. J. Roy. Meteorol. Soc., 120, 861-880, doi:10.1002/qj.49712051806, 1994.

Fenicia, F., Savenije, H. H. G., Matgen, P., and Pfister, L.: Is the groundwater reservoir linear? Learning from data in hy- 
drological modelling, Hydrol. Earth Syst. Sci., 10, 139-150, doi:10.5194/hess-10-139-2006, 2006.

Gerrits, A. M. J., Savenije, H. H. G., Veling, E. J. M., and Pfister, L.: Analytical derivation of the Budyko curve based on rainfall characteristics and a simple evaporation model, Water Resour. Res., 45, W04403, doi:10.1029/2008wr007308, 2009.

Gerrits, A. M. J., Pfister, L., and Savenije, H. H. G.: Spatial and temporal variability of canopy and forest floor interception in a beech forest, Hydrol. Process., 24, 3011-3025, doi:10.1002/hyp.7712, 2010.

Goessling, H. F. and Reick, C. H.: What do moisture recycling estimates tell us? Exploring the extreme case of nonevaporating continents, Hydrol. Earth Syst. Sci., 15, 3217-3235, doi:10.5194/hess-15-3217-2011, 2011.

Higgins, R. W., Yao, Y., and Wang, X. L.: Influence of the North American monsoon system on the US summer precipitation regime, J. Climate, 10, 2600-2622, doi:10.1175/15200442(1997)010<2600:iotnam>2.0.co;2, 1997.

Howell, T. A. and Evett, S. R.: The Penman-Monteith method, in: Evapotranspiration: Determination of Consumptive Use in Water Rights Proceedings, Continuing Legal Education in Colorado, Inc. Denver, Colorado, 2004.

Koster, R. D., Dirmeyer, P. A., Guo, Z., Bonan, G., Chan, E., Cox, P., Gordon, C. T., Kanae, S., Kowalczyk, E., Lawrence, D., Liu, P., Lu, C. H., Malyshev, S., McAvaney, B., Mitchell, K., Mocko, D., Oki, T., Oleson, K., Pitman, A., Sud, Y. C., Taylor, C. M., Verseghy, D., Vasic, R., Xue, Y., and Yamada, T.: Regions of strong coupling between soil moisture and precipitation, Science, 305, 1138-1140, doi:10.1126/science.1100217, 2004.

Kunstmann, H. and Jung, G.: Influence of soil-moisture and land use change on precipitation in the Volta Basin of West Africa, International Journal of River Basin Management, 5, 9-16, doi:10.1080/15715124.2007.9635301, 2007.

Langmuir, I.: The constitution and fundamental properties of solids and liquids. Part I. Solids, J. Am. Chem. Soc., 38, 2221-2295, doi:10.1021/ja02268a002, 1916.

Lintner, B. R., Gentine, P., Findell, K. L., D’Andrea, F., and Sobel, A. H.: An idealized prototype for large-scale land-atmosphere coupling, J. Climate, pending with minor revisions, 2012.

Matsoukas, C., Benas, N., Hatzianastassiou, N., Pavlakis, K. G., Kanakidou, M., and Vardavas, I.: Potential evaporation trends over land between 1983-2008: driven by radiative fluxes or vapour-pressure deficit?, Atmos. Chem. Phys., 11, 7601-7616, doi:10.5194/acp-11-7601-2011, 2011.

Monteith, J. L.: Evaporation and environment, Proc. Symp. Soc. Exp. Biol., 19, 205-234, 1965.

Pisso, I., Real, E., Law, K. S., Legras, B., Bousserez, N., Attié, J. L., and Schlager, H.: Estimation of mixing in the troposphere from Lagrangian trace gas reconstructions during longrange pollution plume transport, J. Geophys. Res., 114, D19301, doi:10.1029/2008JD011289, 2009.

Pitman, A. J., de Noblet-Ducoudre, N., Cruz, F. T., Davin, E. L., Bonan, G. B., Brovkin, V., Claussen, M., Delire, C., Ganzeveld, L., Gayler, V., van den Hurk, B. J. J. M., Lawrence, P. J., van der Molen, M. K., Muller, C., Reick, C. H., Seneviratne, S. I., Strengers, B. J., and Voldoire, A.: Uncertainties in climate responses to past land cover change: First results from the LUCID intercomparison study, Geophys. Res. Lett., 36, L14814, doi:10.1029/2009GL039076, 2009
Priestley, C. H. B. and Taylor, R. J.: On the assessment of surface heat flux and evaporation using large-scale parameters, Mon. Weather Rev., 100, 81-92, doi:10.1175/15200493(1972)100<0081:OTAOSH>2.3.CO;2, 1972.

Randel, D. L., Vonder Haar, T. H., Ringerud, M. A., Stephens, G. L., Greenwald, T. J., and Combs, C. L.: A New Global Water Vapor Dataset, B. Am. Meteorol. Soc., 77, 1233-1246, doi:10.1175/15200477(1996)077<1233:ANGWVD>2.0.CO;2, 1996.

Savenije, H. H. G.: New definitions for moisture recycling and the relationship with land-use changes in the Sahel, J. Hydrol., 167, 57-78, doi:10.1016/0022-1694(94)02632-L, 1995a.

Savenije, H. H. G.: Does moisture feedback affect rainfall significantly?, Phys. Chem. Earth, 20, 507-513, doi:10.1016/S00791946(96)00014-6, 1995b.

Savenije, H. H. G.: The Runoff Coefficient as the Key to Moisture Recycling, J. Hydrol., 176, 219-225, doi:10.1016/00221694(95)02776-9, 1996.

Savenije, H. H. G.: The importance of interception and why we should delete the term evapotranspiration from our vocabulary, Hydrol. Process., 18, 1507-1511, doi:10.1002/hyp.5563, 2004.

Schär, C., Lüthi, D., and Beyerle, U.: The soil-precipitaiton feedback: a process study with a regional climate model, J. Climate, 12, 722-741, doi:10.1175/15200442(1999)012<0722:TSPFAP > 2.0.CO;2, 1999.

Schreiber, P.: Über die Beziehungen zwischen dem Niederschlag und der Wasserführung der Flüsse in Mitteleuropa, Z. Meteorol., 21, 441-452, 1904.

Seneviratne, S. I., Corti, T., Davin, E. L., Hirschi, M. Jaeger, E. B., Lehner, I., Orlowsky, B., and Teuling, A. J.: Investigating soil moisture-climate interactions in a changing climate: A review, Earth-Sci. Rev., 99, 125-161, doi:10.1016/j.earscirev.2010.02.004, 2010.

Sultan, B. and Janicot, S.: The West African monsoon dynamics. Part II: The "preonset" and "onset" of the summer monsoon, J. Climate, 16, 3407-3427, doi:10.1175/15200442(2003)016<3407:TWAMDP>2.0.CO;2, 2003.

Tian, L., Yao, T., MacClune, K., White, J. W. C., Schilla, A., Vaughn, B., Vachon, R., and Ichiyanagi, K.: Stable isotopic variations in west China: A consideration of moisture sources, J. Geophys. Res.-Atmos., 112, D10112, doi:10.1029/2006jd007718, 2007.

Trenberth, K. E.: Atmospheric moisture residence times and cycling: implications for rainfall rates and climate change, Climatic Change, 39, 667-694, 1998.

Trenberth, K. E.: Climate system modeling, Cambridge University Press, Cambridge, 2009.

Trenberth, K. E., Dai, A., Rasmussen, R. M., and Parsons, D. B.: The changing character of precipitation, B. Am. Meteorol. Soc., 84, 1205-1217, doi:10.1175/BAMS-84-9-1205, 2003.

Troch, P. A., Martinez, G. F., Pauwels, V. R. N., Durcik, M., Sivapalan, M., Harman, C., Brooks, P. D., Gupta, H. V., and Huxman, T.: Climate and vegetation water use efficiency at catchment scales, Hydrol. Process., 23, 2409-2414, doi:10.1002/hyp.7358, 2009.

Tuinenburg, O. A., Hutjes, R. W. A., Jacobs, C. M. J., and Kabat, P.: Diagnosis of local land-atmosphere feedbacks in India, J. Climate, 24, 251-266, doi:10.1175/2010JCLI3779.1, 2011. 
van der Ent, R. J. and Savenije, H. H. G.: Length and time scales of atmospheric moisture recycling, Atmos. Chem. Phys., 11, 18531863, doi:10.5194/acp-11-1853-2011, 2011.

Van der Ent, R. J., Savenije, H. H. G., Schaefli, B., and Steele-Dunne, S. C.: The origin and fate of atmospheric moisture over continents, Water Resour. Res., 46, W09525, doi:10.1029/2010WR009127, 2010.

Voepel, H., Ruddell, B., Schumer, R., Troch, P. A., Brooks, P. D., Neal, A., Durcik, M., and Sivapalan, M.: Quantifying the role of climate and landscape characteristics on hydrologic partitioning and vegetation response, Water Resour. Res., 47, W00J09, doi:10.1029/2010wr009944, 2011.
Wagener, T., Sivapalan, M., Troch, P. A., and Woods, R.: Catchment classification and hydrologic similarity, Geography Compass, 1, 901-931, doi:10.1111/j.1749-8198.2007.00039.x, 2007.

Woods, R. A.: Analytical model of seasonal climate impacts on snow hydrology: Continuous snowpacks, Adv. Water Resour., 32, 1465-1481, doi:10.1016/j.advwatres.2009.06.011, 2009.

Worden, J., Noone, D., and Bowman, K.: Importance of rain evaporation and continental convection in the tropical water cycle, Nature, 445, 528-532, doi:10.1038/nature05508, 2007. 